\title{
How do P-Type ATPases transport ions?
}

\author{
Hans-Jürgen Apell* \\ Department of Biology, University of Konstanz, Fach M635, 78464 Konstanz, Germany
}

Received 20 July 2003; received in revised form 29 August 2003; accepted 3 September 2003

\begin{abstract}
P-type ATPases are a large family of membrane proteins that perform active ion transport across biological membranes. In these proteins, the energy-providing ATP hydrolysis is coupled to ion transport of one or two ion species across the respective membrane. The pump function of the investigated pumps is described by a so-called Post-Albers cycle. Main features of the pumping process are (1) a Ping-Pong mechanism, i.e. both transported ion species are transferred successively and in opposite direction across the membrane, (2) the transport process for each ion species consists of a sequence of reaction steps, which are ion binding, ion occlusion, conformational transition of the protein, successive deocclusion of the ions and release to the other side of the membrane. (3) Recent experimental evidence shows that the ion-binding sites are placed in the transmembrane section of the proteins and that ion movements occur preferentially during the ion binding and release processes. The main features of the mechanism include narrow access channels from both sides, one gate per access channel, and an ion-binding moietv that is adapted specifically to the ions that are transported, and differently in both principal conformations.
\end{abstract}

Keywords: Na,K-ATPase; Ca-ATPase; H,K-ATPase; Ion transport; Electrogenicity

\section{Introduction}

P-type ATPases are a family of primary, active ion transporters which are found in virtually all eucaryotic cells and also in bacteria, and they are transporters of a broad variety of ions $[1,2]$. They utilize the Gibbs free energy of ATP hydrolysis to build up electrochemical potential gradients for the transported ions across the respective membranes.

Advancements in the studies on other active ion-transporting proteins, such as bacteriorhodopsin $[3,4]$ or the $\mathrm{F}_{0} \mathrm{~F}_{1}$-ATPases $[5,6]$, led to concepts on the ion-pump mechanism that are understood in great detail. For these ion pumps, scaled-down concepts of well-known macroscopic machines, such as mechanic pumps or water-driven mills, can be used to describe the highly specific machines of dimensions in the nanometers range. In the case of the P-type ATPases, such a comprehensive understanding is still lacking. First structural details on the atomic scale are now becoming available, and mechanistic constraints are concluded from functional studies in which ion transport is investigated, preferentially by electrophys-

\footnotetext{
* Tel.: +49-7531-882253; fax: +49-7531-883183.

E-mail address: h-j.apell@uni-konstanz.de (H.-J. Apell).
}

iological and optical methods [1]. So far, however, no mechanistic concept of the energy transduction could be formulated.

In the family of P-type ATPases, three members were investigated to much greater detail than all others. The first and best investigated ion pump is the Na,K-ATPase which is a house-keeping enzyme in almost all animal cells and which maintains the electrochemical potential gradients for $\mathrm{Na}^{+}$and $\mathrm{K}^{+}$ions across the cytoplasmic membrane. The second protein is the Ca-ATPase of the sarcoplasmatic reticulum (SR Ca-ATPase) which pumps $\mathrm{Ca}^{2+}$ ions back into the lumen of the sarcoplasmatic reticulum causing muscle relaxation by reducing the cytoplasmic $\mathrm{Ca}^{2+}$ to concentrations less than $0.1 \mu \mathrm{M}$. The third pump is the gastric H,K-ATPase which is expressed in parietal cells of the gastric mucosa where it drives the hydrochloric-acid secretion into the stomach lumen by active transport of $\mathrm{H}^{+}$, followed by passive transport of $\mathrm{Cl}^{-}$.

\section{Structural properties}

So far, crystal structures with atomic resolution are available only for one species, the SR Ca-ATPase. It was a breakthrough in the understanding of structure-function 
relationships when the first highly resolved 3D structure of the Ca-ATPase of the sarcoplasmatic reticulum in its $E_{1}$ conformation with $2 \mathrm{Ca}^{2+}$ ions bound (" $\mathrm{Ca}_{2} \mathrm{E}_{1}$ ") [7] became available with a resolution of $2.6 \AA$ (Fig. 1A). This structure confirms the topological organization of ten transmembrane helices which was deduced for $\mathrm{Ca}, \mathrm{Na}, \mathrm{K}-$, and H,K-pumps by biochemical techniques [8], however, the structure reveals several unexpected features. It was found [7] that (a) both ions are located side by side with a distance of $5.7 \AA$ close to the middle of the transmembrane section of the protein, (b) the ion-binding sites are surrounded by the transmembrane helices M4-M6 and M8, (c) the $\alpha$ helices M4 and M6 are partly unwound to provide an efficient coordination geometry for the two $\mathrm{Ca}^{2+}$ ions, and (d) a cavity with a rather wide opening, surrounded by M2, M4 and M6 is discussed as an access structure on the cytoplasmic side. The outlet of $\mathrm{Ca}^{2+}$ is likely to be located in the area surrounded by M3-M5. The parts of the protein protruding into the cytoplasm are divided into three domains, two domains, $\mathrm{N}$ (nucleotide) and $\mathrm{P}$ (phosphoryla- tion), are formed by the loop between M4 and M5, well separated from a third A domain (actuator or anchor) formed by the loop between M2 and M3 and the tail leading into M1.

As a second structure of the SR Ca-ATPase, an $\mathrm{E}_{2}$ conformation stabilized by the specific inhibitor tharpsigargin (" $\mathrm{E}_{2}(\mathrm{TG})$ "), became available with a resolution of $3.1 \AA[9]$ (Fig. 1B). Due to the low $\mathrm{Ca}^{2+}$-binding affinity of the $E_{2}$ state of the protein, it was not possible to obtain crystals with $\mathrm{Ca}^{2+}$ ions bound which would allow a direct determination of the position of the binding sites of this conformation.

Despite the previously often discussed concept that no major structural rearrangements are expected in the membrane domains between different conformations of the pump, the reported changes of position and tilt of the first six transmembrane helices are dramatic (Fig. 1C,D). The rearrangement of the membrane helices during the transition from the $E_{1}$ to $E_{2}$ state disrupts the almost perfect coordination of the two $\mathrm{Ca}^{2+}$ ions, thus explaining the decrease of
A

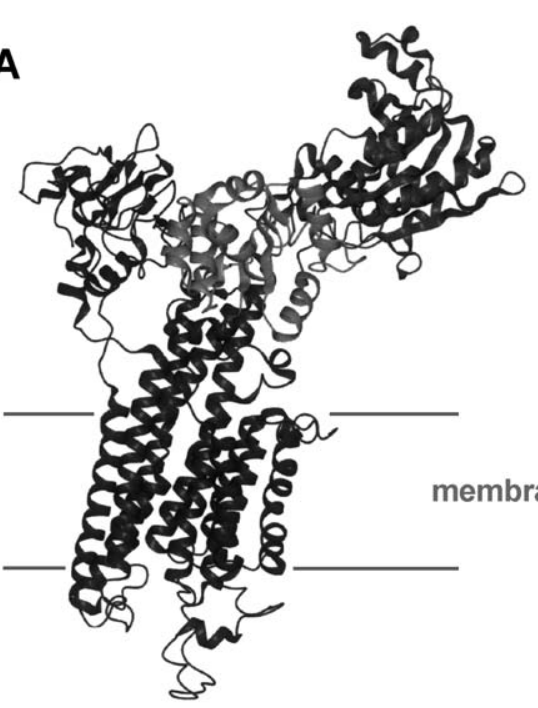

$\mathrm{Ca}_{2} \mathrm{E}_{1}$

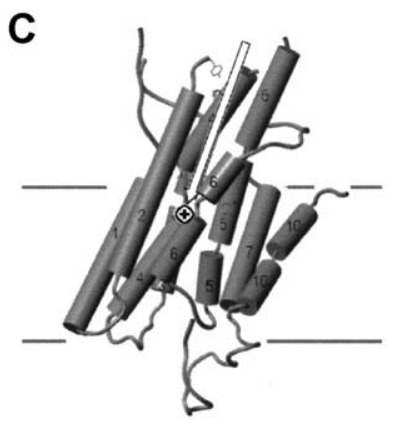

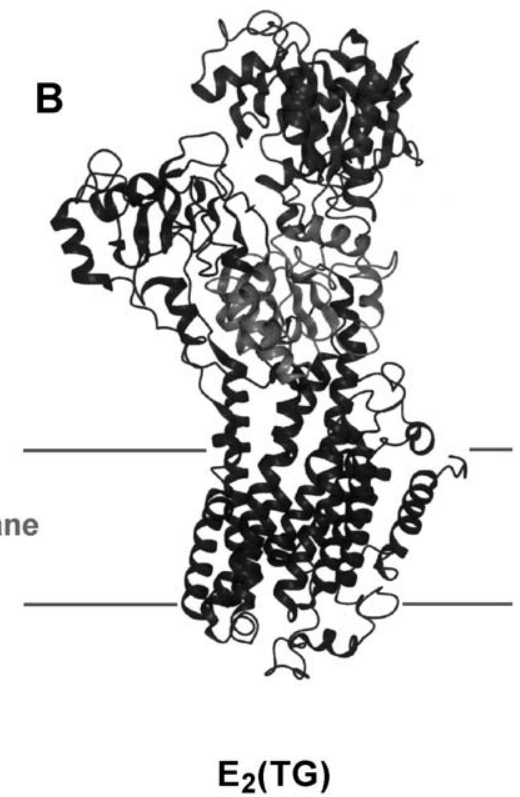

D

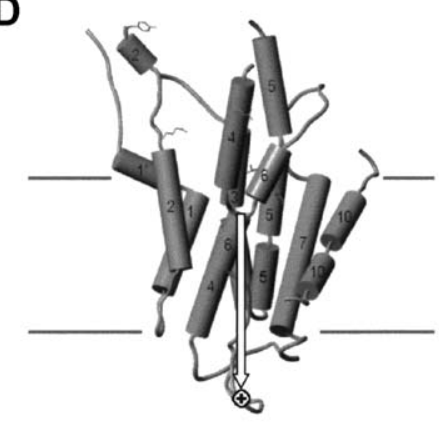

Fig. 1. Structure of the Ca-ATPase of the sarcoplasmatic reticulum in both principal conformations as resolved by their crystal structure. (A) In its conformation $\mathrm{Ca}_{2} \mathrm{E}_{1}$ (PDB file 1EUL), the spatial resolution was $2.6 \AA$ [7]. (B) The structure in the $\mathrm{E}_{2}$ conformation (PDB File 1IWO) was stabilized by tharpsigargin (not shown), $\mathrm{E}_{2}$ (TG) and obtained from crystals with a resolution of $3.1 \AA$ [9]. Details of the arrangement of the membrane helices of the SR Ca-ATPase in both resolved conformations, $\mathrm{Ca}_{2} \mathrm{E}_{1}(\mathrm{C})$ and $\mathrm{E}_{2}(\mathrm{TG})(\mathrm{D})$ with proposed access pathways to the ion-binding sites inside the membrane (adapted from Ref. [9]). 
the binding affinity by more than three orders of magnitude may be explained. For more details, confer Ref. [9].

So far the SR Ca-ATPase is the only P-type ATPase for which such a detailed structural resolution is available. From other members of this family, only images with a lower resolution of about $8 \AA$ are available [10-12]. A comparison of such images with a similarly resolved SR CaATPase structure [13] indicates that they agree in most of the important structural details.

The enzymatic part of all P-type ATPases is formed mainly by the cytoplasmic loops L23, L45 and the N terminus of the $\alpha$ subunit, and it is well conserved in all species investigated so far. The structure of the membrane part of the protein, which performs ion-transport function, consists of 10 transmembrane segments whose amino-acid sequences are rather similar for all three pumps. However, specific differences in the amino-acid sequences were found with respect to charge and polarity, accounting for the different functional properties, which may be summarized by their transport stoichiometry: $3 \mathrm{Na}^{+} / 2 \mathrm{~K}^{+} / 1 \mathrm{ATP}$ for the $\mathrm{Na}, \mathrm{K}$-ATPase, $2 \mathrm{H}^{+} / 2 \mathrm{~K}^{+} / 1 \mathrm{ATP}$ for the $\mathrm{H}, \mathrm{K}$-ATPase and $2 \mathrm{Ca}^{2+} / 2 \mathrm{H}^{+} / 1 \mathrm{ATP}$ for the SR Ca-ATPase.

\section{Functional properties}

The pump function of all three ion pumps can be described by a so-called Post-Albers cycle (Fig. 2). Main features of the pumping process are (1) a Ping-Pong mechanism, i.e. both transported ion species are transferred successively and in opposite direction across the membrane, (2) the transport process for each ion species consists of a sequence of reaction steps: ion binding, ion occlusion (in combination with enzyme phosphorylation or dephosphor-

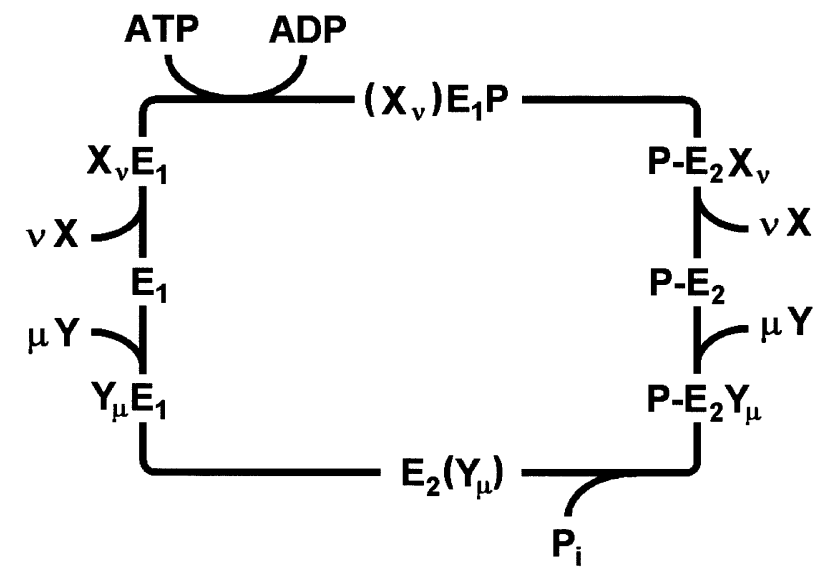

Fig. 2. Post-Albers cycle for the P-type ATPase. $E_{1}$ and $E_{2}$ are conformations of the ion pump with ion-binding sites facing the cytoplasm and extracellular medium, respectively. $v$ ions of species $\mathrm{X}$ and $\mu$ of species $\mathrm{Y}$ are transported out of and into the cytoplasm of the cell, respectively. $\left(\mathrm{X}_{v}\right) \mathrm{E}_{1}-\mathrm{P}$, and $\mathrm{E}_{2}\left(\mathrm{Y}_{\mu}\right)$ are occluded states in which the ions bound are unable to exchange with either aqueous phases. Enzyme phosphorylation and dephosphorylation occur on the cytoplasmic side of the protein. ylation), conformational transition of the protein, successive deocclusion of the ions and release to the other side of the membrane.

An ion transport by a membrane protein is called electrogenic when net charge is moved across the membrane, and thus affects the membrane potential by charging or discharging the membrane capacitance (depending on the direction of the charge movement). Conversely, the charge transport by electrogenic ion transporters may be modulated by the membrane potential [14]. This definition of electrogenicity was originally introduced for the whole transport cycle of ion pumps. On this basis, an overall electrogenicity of the Na,K-ATPase and SR Ca-ATPase is given, which transfer one or two positive elementary charges across the membrane, respectively. The transport of the $\mathrm{H}, \mathrm{K}$-ATPase is not electrogenic since its stoichiometry is $2 \mathrm{H}^{+} / 2 \mathrm{~K}^{+}$per transport cycle. Because it is possible to restrict the transport process experimentally to half cycles in which only one ion species is translocated, it was found that both $\mathrm{H}^{+}$and $\mathrm{K}^{+}$ transport translocate net charge across the membrane. Therefore, the definition of 'electrogenicity' was introduced also for partial reactions of the transport cycle $[1,15]$.

\subsection{Fluorescence techniques for detection of electrogenic partial reactions}

In the case of the $\mathrm{Na}, \mathrm{K}-\mathrm{ATPase}$, electrophysiological techniques were widely applied to investigate the various electrogenic reaction steps of the Post-Albers cycle. Similar investigations cannot be easily performed with the SR CaATPase, since the (leak) conductance of the SR membrane is high due to its permeability for monovalent ions so that both aqueous phases are electrically short circuited. In the case of the gastric H,K-ATPase, the isolated ion-pump containing preparation consists of vesicles which are too small to be patched by electrodes, and therefore, no direct electrophysiological methods can be applied. For a review of the various experimental techniques used for P-type ATPases, see Ref. [1].

An alternative experimental approach makes use of lipidsoluble, fluorescent styryl dyes, such as RH237 and RH421, which were used since 1988 to trace pump activity of the $\mathrm{Na}, \mathrm{K}$-ATPase [16,17]. These dyes, and others of the styryl family, are hydrophobic compounds of amphiphilic character, which insert into lipid membranes in an aligned manner [18]. Due to their electrochromic mechanism, they detect changes of local electric fields in the membrane dielectric, and therefore, report charge movements in membrane preparations in which the ion transporters are present in a sufficiently high density $\left(>10^{3}\right.$ per $\left.\mu \mathrm{m}^{2}\right)$ [18]. Styryl dyes are so-called fast dyes since their response times are in a submicrosecond range. They can be applied to membrane vesicles or to flat membranes, such as purified microsomal preparations of the $\mathrm{Na}, \mathrm{K}-\mathrm{ATPase}$, so that not a transmembrane ion transport is detected but movements of ions into the membrane domain of the ion pumps or ion release to the 
aqueous phase [19]. With this method, a wide spectrum of partial reactions of the $\mathrm{Na}, \mathrm{K}$-ATPase was studied and analyzed which led to an advanced understanding of ionbinding affinities [19-22], rate constants of single reaction steps [23-27] and the energetics of the pump cycle [28].

Styryl dyes were also used to investigate ion transport through the SR Ca-ATPase [29,30], and recently, comparable applications to vesicles containing the gastric $\mathrm{H}, \mathrm{K}$ ATPase were demonstrated [31].

\subsection{Electrogenic partial reactions of the NA,K-ATPase, $C A$-ATPase and H,K-ATPase}

Electrogenic transport implies the movement of charge through the protein dielectric. When compared with the Post-Albers scheme of the pumps (Fig. 2), the outwarddirected charge movement occurs in the reaction sequence of (at least) four steps: ion binding, occlusion, conformation transition and ion release (for the sake of simplicity, we assume $v=1), \mathrm{E}_{1} \rightarrow \mathrm{XE}_{1} \rightarrow(\mathrm{X}) \mathrm{E}_{1} \mathrm{P} \rightarrow \mathrm{P}-\mathrm{E}_{2} \mathrm{X} \rightarrow \mathrm{P}-\mathrm{E}_{2}$. To quantify such charge movements, we consider a potentialenergy profile for an ion along its pathway through the membrane which is modified according to the properties of the different states in the half cycle (Fig. 3). The 'dielectric' distance (or 'dielectric coefficient') was introduced as char-

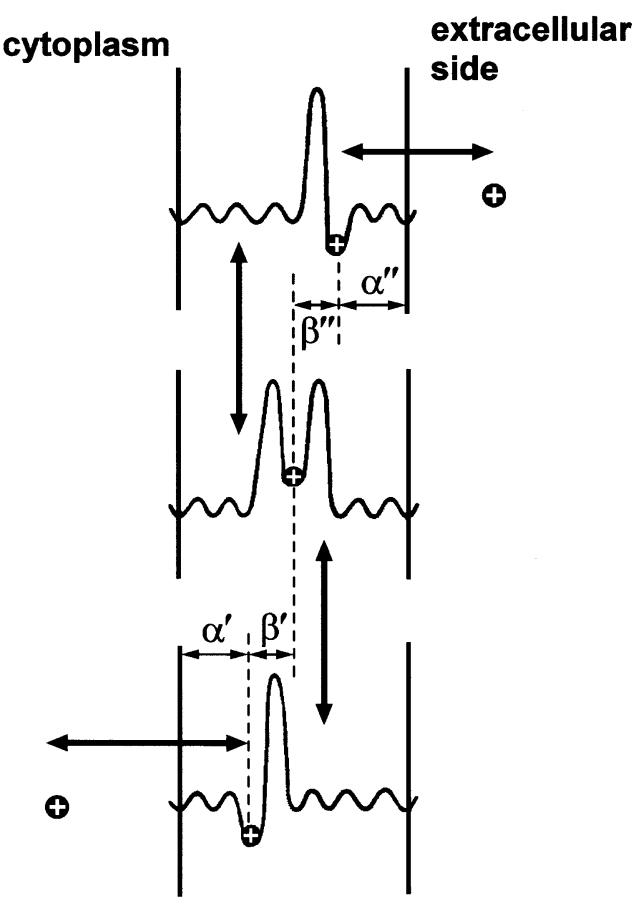

Fig. 3. Potential-energy profile of a transported ion along its pathway in states $\mathrm{XE}_{1},(\mathrm{X}) \mathrm{E}_{1}-\mathrm{P}$ and $\mathrm{P}-\mathrm{E}_{2} \mathrm{X}$. The high energy barriers symbolize a virtually impenetrable structure for the ion. $\alpha^{\prime}, \beta^{\prime}, \beta^{\prime \prime}$ and $\alpha^{\prime \prime}$ represent relative dielectric distances which characterize the fraction of the membrane potential that has to be traversed by ions between two neighboring pump states. In the occluded state, equilibration between binding site and aqueous phase is blocked on both sides. Nonzero values of the dielectric distances correspond to an electrogenic contribution. Dielectric and spatial distances are not necessarily the same.

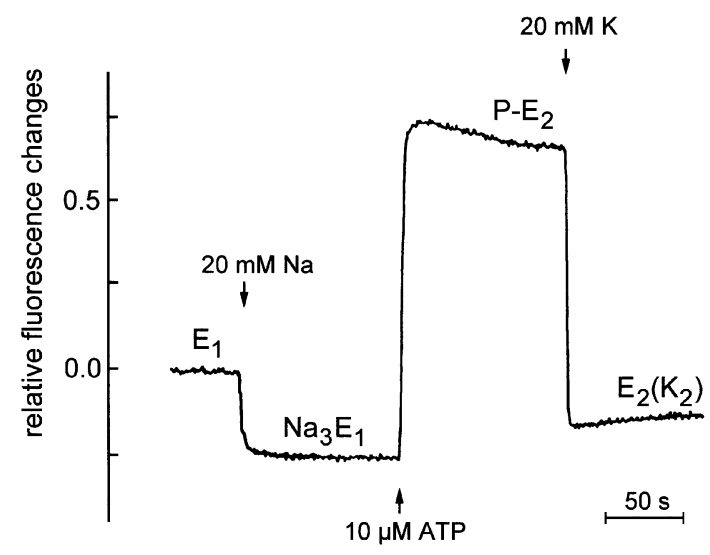

Fig. 4. Fluorescence changes of the styryl dye RH421 bound to Na,KATPase-containing membrane fragments. About $9 \mu / \mathrm{ml}$ protein was equilibrated at $20{ }^{\circ} \mathrm{C}$ with $200 \mathrm{nM}$ RH421 in the presence of $25 \mathrm{mM}$ histidine, $5 \mathrm{mM} \mathrm{MgCl}_{2}$ and $0.5 \mathrm{mM}$ EDTA. The initial fluorescence level reports the specific fluorescence of the ion pump in the absence of $\mathrm{Na}^{+}$and $\mathrm{K}^{+}$ions $\left(\mathrm{E}_{1}\right)$. Addition of $20 \mathrm{mM} \mathrm{NaCl}$ leads into state $\mathrm{Na}_{3} \mathrm{E}_{1}$. The fluorescence decrease by approximately $25 \%$ indicates an import of positive charge into the protein dielectric [18]. Addition of $10 \mu \mathrm{M}$ ATP mediates the transition into state $\mathrm{P}-\mathrm{E}_{2}$ (due to the low $\mathrm{Na}^{+}$binding affinity in $\mathrm{P}-\mathrm{E}_{2}$ ). The fluorescence increase is caused by the release of the three $\mathrm{Na}^{+}$ions. The subsequent addition of $20 \mathrm{mM} \mathrm{KCl}$ caused $\mathrm{K}^{+}$binding, enzyme dephosphorylation and $\mathrm{K}^{+}$occlusion, and is associated with a fluorescence decrease by import of the positive charges.

acteristic parameter to describe the fraction of the membrane dielectric over which the charge is shifted perpendicularly to the plane of the membrane [14]. If a dielectric coefficient is greater than zero, the respective reaction step (according to the Post-Albers scheme) is termed 'electrogenic.' In Fig. 3, for example, the dielectric coefficient for cytoplasmic binding of the cation $\mathrm{X}$ would be $\alpha^{\prime}$. (According to the conservation principle, the condition, $\alpha^{\prime}+\beta^{\prime}+\beta^{\prime \prime}+\alpha^{\prime \prime}=1$, has to be fulfilled for the transfer of each ion across the whole membrane).

A typical fluorescence experiment with the styryl dye RH421 is shown in Fig. 4. It reveals electrogenic partial reaction in the case of the Na,K-ATPase. The fluorescence changes upon substrate addition were produced by cytoplasmic $\mathrm{Na}^{+}$binding, extracellular $\mathrm{Na}^{+}$release and extracellular $\mathrm{K}^{+}$binding [24]. The striking difference of the fluorescence amplitude in binding and release of three $\mathrm{Na}^{+}$ions, as well as the electroneutral release of two $\mathrm{K}^{+}$ions on the cytoplasmic side (not shown), was explained for a long time by the assumption that the two cytoplasmic sites, from which the two $\mathrm{K}^{+}$ions are released and to which the first two $\mathrm{Na}^{+}$ions bind, are located close to the cytoplasmic surface of the protein [15]. When the structure of the SR Ca-ATPase was resolved and clearly showed that the binding sites in this protein are deep inside the membrane domain of the pump, this idea had to be revisited. Either the assumption of a location at the surface had to be sacrificed or one had to propose that the ion-binding sites of the Na,K-ATPase are formed completely different, despite the high homology in the amino-acid sequence between $\mathrm{Na}, \mathrm{K}-\mathrm{ATP}$ ase and SR Ca- 
ATPase. Recent experimental evidence supported affirmatively a localization of the binding sites within the membrane domain [32]. It was found that in the $\mathrm{E}_{1}$ conformation of the $\mathrm{Na}, \mathrm{K}$-ATPase the two binding sites which bind $\mathrm{K}^{+}$or $\mathrm{Na}^{+}$ ions are always occupied in physiological $\mathrm{pH}$, if not by transported cations then by $\mathrm{H}^{+}$ions. (In contrast to the first two sites, the third site is exclusively $\mathrm{Na}^{+}$-selective.) The
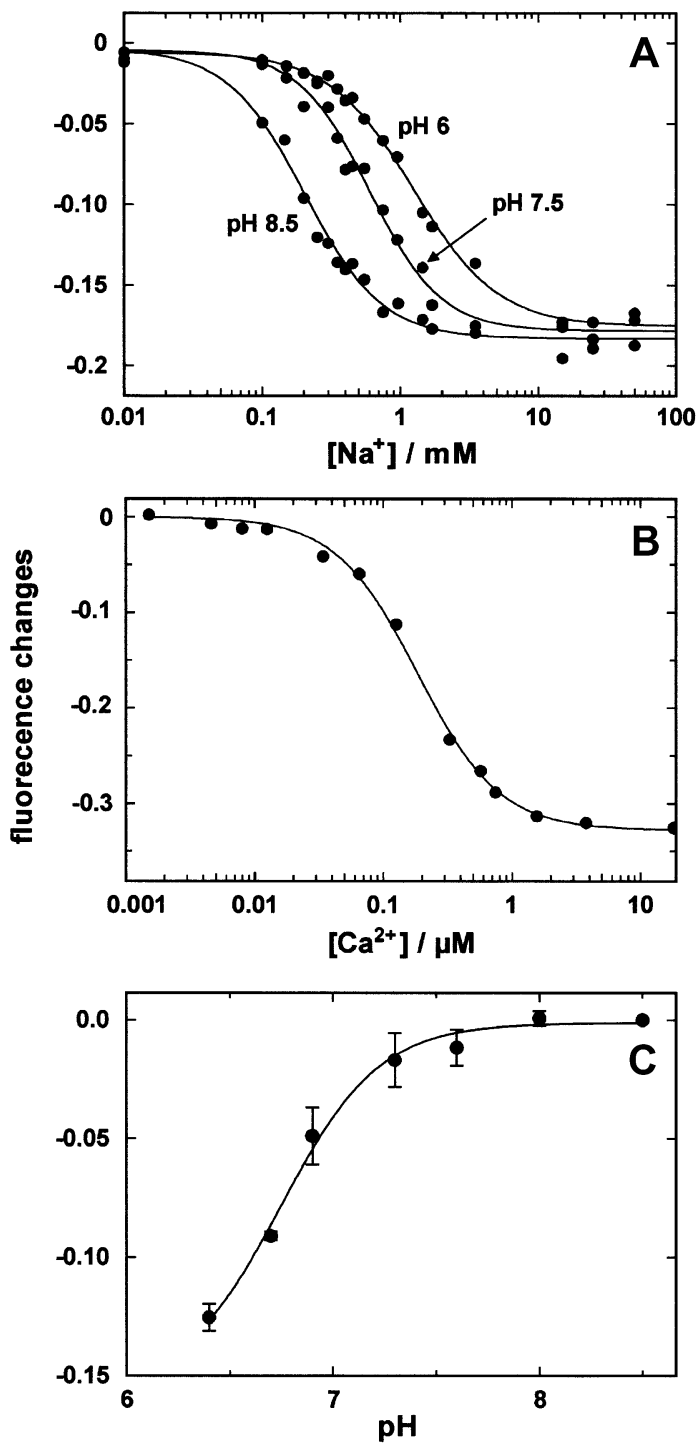

Fig. 5. Electrogenic binding of cations to cytoplasmic binding sites as detected by electrochromic styryl dyes. The fluorescence decrease with increasing ion concentrations indicates import of positive charge into the membrane domain of the ATPases, $\mathrm{E}_{1}+v \mathrm{X} \rightleftarrows \mathrm{X}_{v} \mathrm{E}_{1}$. (A) Na,K-ATPase: $\mathrm{Na}^{+}$ binding in dependence of buffer $\mathrm{pH}$. Experiments were performed in buffer containing $25 \mathrm{mM}$ histidine, $0.5 \mathrm{mM}$ EDTA, $200 \mathrm{nM}$ RH421, $\mathrm{pH}$ was adjusted by $\mathrm{HCl}$ [32]. Aliquots of $\mathrm{NaCl}$ were added until no further fluorescence decrease could be observed. Data were fitted by the Hill function. The half-saturating $\mathrm{Na}^{+}$concentrations were $1.25 \mathrm{mM}(\mathrm{pH} 6), 0.6$ $\mathrm{mM}(\mathrm{pH} 7.5)$ and $0.2 \mathrm{mM}(\mathrm{pH} 8.5)$. (B) Ca-ATPase: $\mathrm{Ca}^{2+}$ binding was studied in buffer containing $25 \mathrm{mM}$ tricine, $50 \mathrm{mM} \mathrm{KCl}, 200 \mathrm{nM}$ 2BITC, $\mathrm{pH} 7.2$ [30]. The half-saturating $\mathrm{Ca}^{2+}$ concentration was $185 \mathrm{nM}$. (C) H,KATPase: $\mathrm{pH}$ titration was starting in buffer containing $25 \mathrm{mM}$ imidazole, 5 $\mathrm{mM} \mathrm{MgCl} 2,1 \mathrm{mM}$ EDTA, $200 \mathrm{nM} \mathrm{RH} 421, \mathrm{pH}$ 8.5. The $\mathrm{pH}$ of $\mathrm{H}^{+}$binding was determined to be 6.7 . competition between $\mathrm{Na}^{+}$and $\mathrm{H}^{+}$ions is shown in Fig. 5A. Therefore, the apparently electroneutral $\mathrm{K}^{+}$release from and $\mathrm{Na}^{+}$binding to the two (unspecific) sites is in fact a cationproton counter-movement by which any net charge movement is hidden [32].

On the basis of this finding, all three investigated P-type ATPases obey the same general mechanism, in which all ionbinding and release steps are the principal electrogenic reactions of the pump cycle. This is demonstrated in Fig. 5 exemplarily for one of these reactions, the cytoplasmic ionbinding reaction (the other ion-moving steps are discussed in Ref. [1]). In equilibrium titration experiments, binding of $\mathrm{Na}^{+}$to the Na,K-ATPase, of $\mathrm{Ca}^{2+}$ to the SR Ca-ATPase and of $\mathrm{H}^{+}$to the H,K-ATPase not only revealed the electrogenicity by the fluorescence decrease, but also allowed in addition the determination of the half-saturating ion concentrations, $K_{! / 2}$. In the case of the Na,K-ATPase, $K_{! / 2}$ is $\mathrm{pH}$ dependent, and a detailed analysis revealed competitive inhibition of the binding of the first $2 \mathrm{Na}^{+}$by $2 \mathrm{H}^{+}$and (net) electrogenic binding of the third to a $\mathrm{H}^{+}$-insensitive site [32]

\section{The ion-transport mechanism}

On the basis of the findings on the electrogenicity of the reaction steps that perform ion translocation through the membrane domain of the three P-type ATPases investigated (Fig. 5), it could be established that the major charge movements occurred during ion binding and release $\left(\alpha^{\prime}\right.$ and $\left.\alpha^{\prime \prime}\right)$. Ion occlusion and the conformation transition $\left(\beta^{\prime}\right.$ and $\beta^{\prime \prime}$ ) were of minor importance. In the case of the $\mathrm{Na}, \mathrm{K}$ ATPase, for which the most detailed investigations are available, it was shown that $\alpha^{\prime}=0.25$ [33], $\beta^{\prime}=0$ [34], $\beta^{\prime \prime}<0.1$, and $\alpha^{\prime \prime}=0.65+0.2+0.2$ [35].

Summarizing the above findings discussed in this presentation, it can be proposed that the high homology in amino-acid sequence and, most probably, a high similarity of the quaternary structure of the three ATPases is complemented by a single concept of the transport mechanism which allows a description of all transport phenomena observed so far. This concept is based on an alternate-access channel model discussed first by Läuger [36]. The main features of the adapted mechanism are shown as cartoon in Fig. 6. They include (1) narrow access channels from both aqueous phases, (2) one gate per access channel and (3) an ion-binding moiety that is adapted specifically and differently to the ions that are transported in both principal conformations.

The transmembrane part of the pump, which is formed by 10 helices of the $\alpha$ subunit and by the one helix of the $\beta$ subunit (in the case of the Na,K-ATPase and H,K-ATPase), is represented in Fig. 6 as shaded box with a cavity inside the membrane. This cavity is connected to the aqueous phases on both sides by narrow access channels. Each half channel possesses a gate that is controlled by the protein conformation (including changes induced by ATP binding 


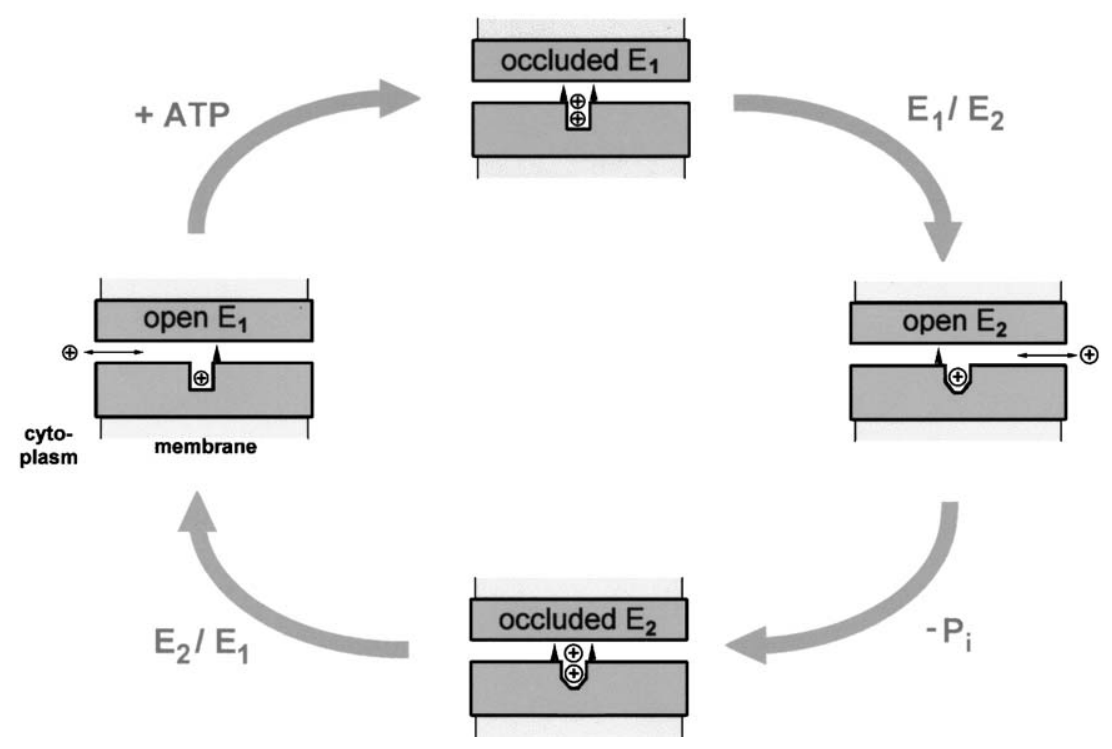

Fig. 6. Schematic representation of the ion transport pathway and ion-binding sites in P-type ATPases. Access to the binding sites from the aqueous phases is controlled by gates that alternately open the pathway. The pump is in an occluded state when both gates lock the access channels. An open state of both gates would produce an ion-channel like behavior and is prohibited under physiological conditions.

as well as by protein phosphorylation/dephosphorylation). A consequence of this arrangement is that ion binding and release is electrogenic on both sides, as required by the experimental findings for all three pumps. Negative (partial) charges in the binding sites are required to coordinate the dehydrated cations and to reduce the Coulomb field of the cations in the largely apolar interior of the transmembrane part of the pump proteins.

The gates which block ion exchange between binding sites and aqueous phase are not necessarily mechanical barriers like floodgates. A look at the 3D structure of the crystallized $\mathrm{Ca}_{2} \mathrm{E}_{1}$ conformation of the Ca-ATPase reveals that there is indeed no steric obstacle in the pathway between the binding sites and the luminal aqueous phase. Therefore, the gates which block the access channels have to be thought as energy barriers produced by an arrangement of amino-acid side chains that do not allow dehydrated ions to be coordinated, and thus make ion propagation energetically extremely unfavorable. In the $\mathrm{E}_{1}$ states, the right hand gate in cartoon of Fig. 6 is "closed", and access for ions is possible only from the cytoplasmic side. Correspondingly, in the states of $E_{2}$, the left gate is closed and ions can enter the binding sites only from the luminal (or extracellular) phase. Occluded states are transient states while the pumps run through their transport cycle and switch back and forth between both principal conformations. Occluded states are characterized by locking the binding moiety from both access channels. They are required to prevent an ion-channel like conformation that would short-circuit both aqueous phases. However, under "unphysiological conditions", a channellike behavior of the Na,K-ATPase could be produced by addition of Palytoxin, a potent marine toxin isolated from Palythoa toxica. In the presence of this compound, electric current fluctuations through the Na,K-ATPase were observed like those of a "classic" ion channel, with fluxes in the order of $10^{6}$ ions per second [37].

The third feature of the mechanistic model is the binding moiety deep inside the membrane domain. In case of the CaATPase, it was found to be inside about $30-40 \%$ of the membrane thickness from the cytoplasmic surface [9]. In this moiety, ion-binding sites are formed in a way that they show differently high binding affinities for the transported ions in both principal conformations. In the case of the SR $\mathrm{Ca}$-ATPase, it was shown by the crystal structure that in the $\mathrm{E}_{1}$ conformation, the two dehydrated $\mathrm{Ca}^{2+}$ ions are perfectly coordinated by amino-acid side chains that mimic a hydration shell. It can also be seen easily that the low $\mathrm{Ca}^{2+}$ affinity state, $\mathrm{E}_{2}(\mathrm{TG})$, is produced by a severe disruption of the steric arrangement that forms ion-coordination in $\mathrm{E}_{1}$ [9]. A corresponding change may be proposed to occur also by the conformation transition between $E_{1}$ and $P-E_{2}$ of the Na,K-ATPase, since an increase of the half-saturating $\mathrm{Na}^{+}$concentration was observed from $\sim 7 \mathrm{mM}$ (in $\mathrm{E}_{1}$ ) to $\sim 400 \mathrm{mM}$ (in $\mathrm{P}-\mathrm{E}_{2}$ ) [24]. After dissociation of the $\mathrm{Na}^{+}$ ions, the moiety forming the binding-sites is thought to relax into a new equilibrium that is able to coordinate $2 \mathrm{~K}^{+}$ions with high affinity $\left(K_{1 / 2} \approx 0.1 \mathrm{mM}\right)[20]$.

When $\mathrm{H}^{+}$ions are bound to these pumps instead of hydronium ions $\left(\mathrm{H}_{3} \mathrm{O}^{+}\right)$, the formation of a complex binding site with an up to six-fold coordination is not necessary, $\mathrm{H}^{+}$ may bind to a single carboxylate anion of an amino-acid side chain. Therefore, "real" binding sites do not have to be formed necessarily for the $\mathrm{P}-\mathrm{E}_{2} \rightarrow \mathrm{E}_{1}$ branch of the SR CaATPase and for the $\mathrm{E}_{1} \rightarrow \mathrm{P}-\mathrm{E}_{2}$ branch of the H,K-ATPase. In Fig. 6 , the different affinity for ions in the binding sites is indicated by the altered shape of the center cavity in the cartoon. 


\section{Coupling of enzymatic and transport function}

Important for the understanding of active ion transport by P-type ATPases is also the energetics of the protein. The Gibbs free energy of ATP hydrolysis, $-\Delta G_{\mathrm{ATP}}$, is transformed into the electrochemical potential gradient for the ion(s) transported across the membrane during a pump cycle. However, so far no information became available, how the chemical energy is used which is transferred to the protein by binding of the $\gamma$-phosphate of ATP to a wellconserved aspartate of the large cytoplasmic loop. The analysis of the free basic energy changes of the various reaction steps around the pump cycle could provide at least clues to the underlying mechanism. Respective investigations with the Na,K-ATPase showed that many steps around the pump cycle are close to thermodynamic equilibrium, and none of the steps could be identified as a kind of power stroke, as known from macroscopic machines [1].

Stimulating input may come from the significant structural changes between the two major conformations which were found in the crystal structure of the SR Ca-ATPase (Fig. 1). The rearrangements of the cytoplasmic domains during the enzymatic activity also affect the membrane domain and, thus, the structure which forms the ion-binding sites within. The "costs" of shifts and turns of the transmembrane helices may be paid by the chemical energy received during phosphorylation. However, a lot of additional structural as well as kinetical and energetical details will have to be collected before a mechanistic model of energy coupling beyond speculation will become available.

\section{Acknowledgements}

This work was supported financially by the Deutsche Forschungsgemeinschaft (AP 45/4) and INTAS (Project 01-0224).

\section{References}

[1] H.-J. Apell, Structure-function relationship in P-Type ATPases-a biophysical approach, Rev. Physiol., Biochem. Pharmacol. 150 (2003) $1-35$.

[2] C. Donnet, E. Arystarkhova, K.J. Sweadner, Thermal denaturation of the Na,K-ATPase provides evidence for alpha-alpha oligomeric interaction and gamma subunit association with the C-terminal domain, J. Biol. Chem. 276 (2001) 7357-7365.

[3] T. Hirai, S. Subramaniam, Structural insights into the mechanism of proton pumping by bacteriorhodopsin, FEBS Lett. 545 (2003) 2-8.

[4] R. Neutze, E. Pebay-Peyroula, K. Edman, A. Royant, J. Navarro, E.M. Landau, Bacteriorhodopsin: a high-resolution structural view of vectorial proton transport, Biochim. Biophys. Acta 1565 (2002) 144-167.

[5] R.H. Fillingame, O.Y. Dmitriev, Structural model of the transmembrane Fo rotary sector of $\mathrm{H}+$-transporting ATP synthase derived by solution NMR and intersubunit cross-linking in situ, Biochim. Biophys. Acta 1565 (2002) 232-245.

[6] V. Muller, G. Gruber, ATP synthases: structure, function and evolution of unique energy converters, Cell. Mol. Life Sci. 60 (2003) 474-494.
[7] C. Toyoshima, M. Nakasako, H. Nomura, H. Ogawa, Crystal structure of the calcium pump of sarcoplasmatic reticulum at $2.6 \AA$ resolution, Nature 405 (2000) 647-655.

[8] D.H. MacLennan, C.J. Brandl, B. Korczak, N.M. Green, Amino-acid sequence of $\mathrm{a} \mathrm{Ca}^{2+} \mathrm{Mg}^{2+}$-dependent ATPase from rabbit muscle sarcoplasmic reticulum, deduced from its complementary DNA sequence, Nature 316 (1985) 696-700.

[9] C. Toyoshima, H. Nomura, Structural changes in the calcium pump accompanying the dissociation of calcium, Nature 418 (2002) 605-611.

[10] H. Hebert, R. Xian, K. Thomsen, A.B. Maunsbach, in: K. Taniguchi, S. Kaya (Eds.), Na/K-ATPase and Related ATPases, Elsevier, Amsterdam, 2000, pp. 43-48.

[11] W. Kühlbrandt, M. Auer, G.A. Scarborough, Structure of the P-type ATPases, Curr. Opin. Struct. Biol. 8 (1998) 510-516.

[12] G.A. Scarborough, Structure and function of the P-type ATPases, Curr. Opin. Cell Biol. 11 (1999) 517-522.

[13] P. Zhang, C. Toyoshima, K. Yonekura, N.M. Green, D.L. Stokes, Structure of the calcium pump from sarcoplasmic reticulum at 8-A resolution, Nature 392 (1998) 835-839.

[14] P. Läuger, Electrogenic Ion Pumps, Sinauer Associates, Sunderland, MA, 1991

[15] H.-J. Apell, S.J.D. Karlish, Functional properties of Na,K-ATPase, and their structural implications, as detected with biophysical techniques, J. Membr. Biol. 180 (2001) 1-9.

[16] R. Bühler, W. Stürmer, H.-J. Apell, P. Läuger, Charge translocation by the Na,K-pump: I. Kinetics of local field changes studied by timeresolved fluorescence measurements, J. Membr. Biol. 121 (1991) $141-161$

[17] I. Klodos, B. Forbush III, Rapid conformational changes of the $\mathrm{Na} / \mathrm{K}$ pump revealed by a fluorescent dye RH-160, J. Gen. Physiol. 92 (1988) 46.

[18] M. Pedersen, M. Roudna, S. Beutner, M. Birmes, B. Reifers, H.-D. Martin, H.-J. Apell, Detection of charge movements in ion pumps by a family of styryl dyes, J. Membr. Biol. 185 (2001) 221-236.

[19] W. Stürmer, R. Bühler, H.-J. Apell, P. Läuger, Charge translocation by the Na,K-pump: II. Ion binding and release at the extracellular face, J. Membr. Biol. 121 (1991) 163-176.

[20] R. Bühler, H.-J. Apell, Sequential potassium binding at the extracellular side of the Na,K-pump, J. Membr. Biol. 145 (1995) 165-173.

[21] A. Schneeberger, H.-J. Apell, Ion selectivity of the cytoplasmic binding sites of the Na,K-ATPase: I. Sodium binding is associated with a conformational rearrangement, J. Membr. Biol. 168 (1999) 221-228.

[22] A. Schneeberger, H.-J. Apell, Ion selectivity of the cytoplasmic binding sites of the Na,K-ATPase: II. Competition of various cations, J. Membr. Biol. 179 (2001) 263-273.

[23] R.J. Clarke, D.J. Kane, H.-J. Apell, M. Roudna, E. Bamberg, Kinetics of $\mathrm{Na}^{+}$-dependent conformational changes of rabbit kidney $\mathrm{Na}^{+}, \mathrm{K}^{+}$ATPase, Biophys. J. 75 (1998) 1340-1353.

[24] S. Heyse, I. Wuddel, H.-J. Apell, W. Stürmer, Partial reactions of the Na,K-ATPase: determination of rate constants, J. Gen. Physiol. 104 (1994) 197-240.

[25] P.A. Humphrey, C. Lupfert, H.J. Apell, F. Cornelius, R.J. Clarke, Mechanism of the rate-determining step of the $\mathrm{Na}(+), \mathrm{K}(+)$-ATPase pump cycle, Biochemistry 41 (2002) 9496-9507.

[26] P.R. Pratap, J.D. Robinson, Rapid kinetic analyses of the $\mathrm{Na}^{+} / \mathrm{K}^{+}$. ATPase distinguish among different criteria for conformational change, Biochim. Biophys. Acta 1151 (1993) 89-98.

[27] N.V. Visser, A. van Hoek, A.J. Visser, J. Frank, H.-J. Apell, R.J. Clarke, Time-resolved fluorescence investigations of the interaction of the voltage-sensitive probe RH421 with lipid membranes and proteins, Biochemistry 34 (1995) 11777-11784.

[28] H.-J. Apell, Kinetic and energetic aspects of $\mathrm{Na}^{+} / \mathrm{K}^{+}$-transport cycle steps, Ann. N.Y. Acad. Sci. 834 (1997) 221-230.

[29] C. Butscher, M. Roudna, H.-J. Apell, Electrogenic partial reactions of the SR-Ca-ATPase investigated by a fluorescence method, J. Membr. Biol. 168 (1999) 169-181. 
[30] C. Peinelt, H.-J. Apell, Kinetics of the $\mathrm{Ca}^{2+}, \mathrm{H}^{+}$and $\mathrm{Mg}^{2+}$ interaction with the ion-binding sites of the SR-Ca-ATPase, Biophys. J. 82 (2002) $170-181$.

[31] A. Diller, O. Vagin, G. Sachs, H.-J. Apell, Electrogenic partial Reactions of the gastric H,K-ATPase, Biophys. J. 84 (2003) 263a.

[32] H.-J. Apell, A. Diller, Do $\mathrm{H}^{+}$ions obscure electrogenic $\mathrm{Na}^{+}$and $\mathrm{K}^{+}$ binding in the E1 state of the Na,K-ATPase? FEBS Lett. 532 (2002) $198-202$.

[33] W. Domaszewicz, H.-J. Apell, Binding of the third $\mathrm{Na}^{+}$ion to the cytoplasmic side of the Na,K-ATPase is electrogenic, FEBS Lett. 458 (1999) 241-246.

[34] R. Borlinghaus, H.-J. Apell, P. Läuger, Fast charge translocations associated with partial reactions of the Na,K-pump: I. Current and voltage transients after photochemical release of ATP, J. Membr. Biol. 97 (1987) 161-178.

[35] I. Wuddel, H.-J. Apell, Electrogenicity of the sodium transport pathway in the Na,K-ATPase probed by charge-pulse experiments, Biophys. J. 69 (1995) 909-921.

[36] P. Läuger, A channel mechanism for electrogenic ion pumps, Biochim. Biophys. Acta 552 (1979) 143-161.

[37] P. Artigas, D.C. Gadsby, $\mathrm{Na}^{+} / \mathrm{K}^{+}$-pump ligands modulate gating of palytoxin-induced ion channels, Proc. Natl. Acad. Sci. U. S. A. 100 (2003) $501-505$. 